\title{
ANALYSIS OF MATERIALS USED IN THE CONSTRUCTION OF ELECTRIC MOTORS
}

\author{
Adelina BORDIANU*, Gheorghe SAMOILESCU** \\ * University Politehnica Bucharest, Bucharest, Romania \\ ** "Mircea cel Bătrân” Naval Academy, Constanța, Romania \\ adelina.bordianu@upb.ro, gheorghe.samoilescu@anmb.ro
}

\begin{abstract}
The paper presents the evolution of electric motors from the point of view of the materials used. Magnetic materials and composite materials, which are used in the construction of electrical machines, are analysed. Composite materials based on magnetic materials have a large coercive field, a wider hysteresis cycle, they cannot be easily demagnetized and they absorb better the vibration energy - therefore the noise is reduced. In the design of electric machines, the aim is to obtain a higher magnetic permeability across the frequency spectrum and to reduce the losses in iron and copper. We analysed the radial electric motors with cylindrical magnets, electric motors in discoidal form with axial field and motors with magnets with transverse flux. Hard magnetic materials were presented and the advantage of their use was highlighted - they retain a significant residual magnetization which translates into a significant saturation magnetization. The synthesis of $\mathrm{Fe}$ nanoparticles is performed and the composite materials obtained from iron powders with organic or inorganic binders are analysed with the purpose of reducing iron losses in electric motors.
\end{abstract}

Keywords: electric motors, composite materials, magnetic permeability, magnetic materials

\section{Introduction}

Since 1882, once Nikola Tesla has identified the principle of the spinning magnetic field, the scientific world has entered a new era. This principle is the basis for the operation of alternating current electric motors and, next to the law of electromagnetic induction, is the basis of electric machines where the operation is based on the mutual electromagnetic action between the stator and the rotor.

Magnetic materials may be: diamagnetic characterized by a low and negative value of magnetic susceptibility; paramagnetic are nonlinear, have positive values of susceptibility and the magnetic permeability depends on the applied field; ferromagnetic - have spontaneous magnetization, nonzero even in the absence of external magnetic fields and the magnetic moments of neighboring atoms form magnetization domains; ant ferromagnetic - the atoms magnetic moments are oriented antiparallel with a total compensation of the resulting moment; ferromagnetic - magnetic moments are antiparallel and different in size so that spontaneous magnetizations of the domains do not compensate $[1,2,3]$.

The composite materials are isotropic from magnetic point of view and are made from mixtures of fine iron powders coated with an organic or inorganic binder. They have low iron losses with special mechanical, 
thermal and magnetic properties. These materials also act as electrical insulators due to the presence of a binder that reduces the amplitude of the eddy currents and limits electromagnetic disturbances by reducing the earth leakage currents.

Polymer matrix composite materials and magnetic inclusions (ferro- or ferrimagnetic) are used to absorb electromagnetic waves [4, 5].They are known to have a weak coercive field due to the hysteresis cycle which is much smaller than permanent magnets. Soft magnetic materials are also used in the manufacture of low frequency electric machines. These can be $[5,6,7]$ laminated, based on iron mixed with cobalt or nickel. $\mathrm{Sm}_{2} \mathrm{Fe}_{17} \mathrm{~N}_{\mathrm{x}}$ compound is characterized by a good saturation magnetization $\left(1,54 \mathrm{~T}\right.$ at $\left.20^{\circ} \mathrm{C}\right)$ and $\mathrm{SmFe}$ compound has a magnetic induction of $0.8 \mathrm{~T}$, a coercive field of $1 \mathrm{MA} /$ $\mathrm{m}$ and an energy of $110 \mathrm{KJ} / \mathrm{m}^{3}$. FeCo compound are expensive, have high permeability and resistivity, have a high saturation polarization, but have the advantage of reducing the volume and mass of the magnetic circuit, and provide a reduction in iron losses compared to $\mathrm{FeSi}$ plates $(5 \mathrm{~W} / \mathrm{kg}$ at $2 \mathrm{~T}$ and $50 \mathrm{~Hz}$ and $45 \mathrm{~W} /$ $\mathrm{kg}$ at $400 \mathrm{~Hz}$ and $2 \mathrm{~T}$ ).

Composite materials with hard magnetic inclusions are used in the manufacture of coils, in the construction of brushless electric motors and step by step motors $[8,9]$.

The electro technical materials used in the construction of electric motors are the electric conductors and magnetic materials, the insulating materials, which make the insulation of the winding, and the materials necessary for the transmission of mechanical couplings. To limit eddy current losses occurring in electric motors, magnetic alloys are used in the form of isolated sheets. Sheets (plates) for high frequency $(400 \mathrm{~Hz})$ where they combined high saturation and low mass loss were made.

The main material used in the alloys is iron, whose low resistivity $\left(10^{-7} \Omega \mathrm{m}\right)$ leads to very high losses under alternate regime [7].
The objective of the alloys is, first, to increase this resistivity. Adding silicon increases the magnetic performance (polarization, temperature) and brings stiffness.

Radial motors with cylindrical magnets are preferred for their ease of construction and have the advantage of being able to be used for high power and low speed applications. They provide significant dimensional design flexibility, allow a reduction in propeller diameter compared to conventional synchronous machines (they require large sizes with low yields). These machines have a larger number of pole pairs and the stator losses by Joule effect are small compared to winding rotor machines, thus allowing a significant reduction in the cost of manufacturing [10].

Engines with discoidal magnets and axial field have fixed discs and moving discs that support permanent magnets. The advantage of the discoidal structure with respect to the cylindrical structures is the optimization of the useful torque generation area, which results in high power density. Increasing polarity in this type of machine has the same effect as on radial field structures and results in a decrease in length. In these types of electric motors, there are drawbacks due to mechanical stresses related to axial tractions and thermal deviations due to the difficulties of evacuating the stator losses $[10,11]$.

Magnet motors with transverse flux have horseshoe-shaped magnetic circuits surrounding the stator winding of each phase. A transverse flux motor comprises several magnetic circuits mounted on the same axis and displaced at a geometric angle of $2 \pi / q$, where $q$ is the number of notches corresponding to one pole. Due to strong pulse couples, vibration and excessive iron losses due to the threedimensional nature of the field they are used for the high torque density requirements, yet its mechanical complexity and cost of implementation make it remain in the field of research $[10,12,13,14]$. To 
reduce these losses, composite magnetic materials (compact powder) are used.

By making a comparison between the asynchronous machine, which offers an alternative in the naval propulsion due to the robustness, cost and simplicity of the machine, and the synchronous machine with magnets, that has the larger Joule losses on the rotor but can withstand a higher temperature rise, the applications gave gain to the asynchronous one.

By comparison, permanent magnet machines are smaller in size and weight than the winding machine. The permanent magnet machine and the "improved" asynchronous machine have almost the same space saving gain of the order of $30 \%$ to $40 \%$ and a weight gain of $25 \%$ to $30 \%$ compared to winding rotor machines [10].

\section{Permanent Magnets and Magnetic Composite Materials}

Permanent magnets are characterized mainly by their hysteresis cycles and especially by the demagnetization curve where we have: the remnant induction - $\mathrm{Br}$; coercive field - Hc; the energy product of volume - $(\mathrm{BH}) \max$; the $\mathrm{Bm}$ and $\mathrm{Hm}$ values of the optimal operating point $M$ corresponding to $(\mathrm{BH})$ max; magnetizing HcJ, coercive field that cancels the intrinsic magnetization of the material. Permanent magnets are field sources. This differs according to residual magnetic induction, coercive field, and life cycle $[3,5]$.

The coercive field is the demagnetization field that cancels the induction, and the higher it's his value the more stable the magnet is. They are magnets with a residual $\mathrm{Br}$ induction of approximately $0.7 \mathrm{~T}$ for isotropes and $1.2 \mathrm{~T}$ for anisotropes, with a low value of the coercive magnetization field $(\mathrm{HcJ})$ ranging from 40 to $80 \mathrm{~A} / \mathrm{m}$. Improving the coercion can be done using Niobium. Ferrites are compounds of iron oxide, barium and strontium. They are obtained by sintering and may be isotropic or anisotropic. These magnets have a modest performance but have become essential in many applications due to low cost and high magnetic rigidity.

Rare earths, such as Samarium-Cobalt and Neodymium-Iron-Boron, are efficient in terms of energy density. Samarium-Cobalt allows a high operating temperature (up to $350{ }^{\circ} \mathrm{C}$ ), but they are very expensive due to the presence cobalt in their composition. In high power machines, considering the volume of magnets used and the associated cost, it is preferable to use neomium-boronboron (Nd-Fe-B) magnets [2,5].

The most common methods of synthesis of magnetic nanoparticles are: physical vapor deposition [15], mechanical (grinding) $[16,17]$ and chemical synthesis in solution $[18,19,20,21]$. Both in the vapor phase and in the solution, the particles are composed of individual atoms. Nanostructures can be obtained by mechanical means by grinding some alloys (in bulk state).

Chemical methods for the production of magnetic nanoparticles are preferred because of their increased molecular homogeneity, cost-effectiveness of production, particle size control and particle size distribution, morphology and conglomerate size.

For magnetic applications the most commonly used are composite materials with polymeric matrix and magnetic inclusions in the form of powder (ferrite, iron, nickel, etc.). Magnetic composite materials, depending on the type of inclusion, are [2]:

- composite materials with soft magnetic inclusions are that used for: transformers, impedance coils, sensors, measuring instruments, frequency converters, signal transformers, magnetic screens, magnetostrictive converters, etc.

- composite materials with hard magnetic inclusions that are used for: brushless current motors, ABS sensors (Antilock Brake System), coils used in engine construction, various couplings, loudspeakers, generators, step by step motors, sensors, etc.

The result is a macroscopically homogeneous material with high 


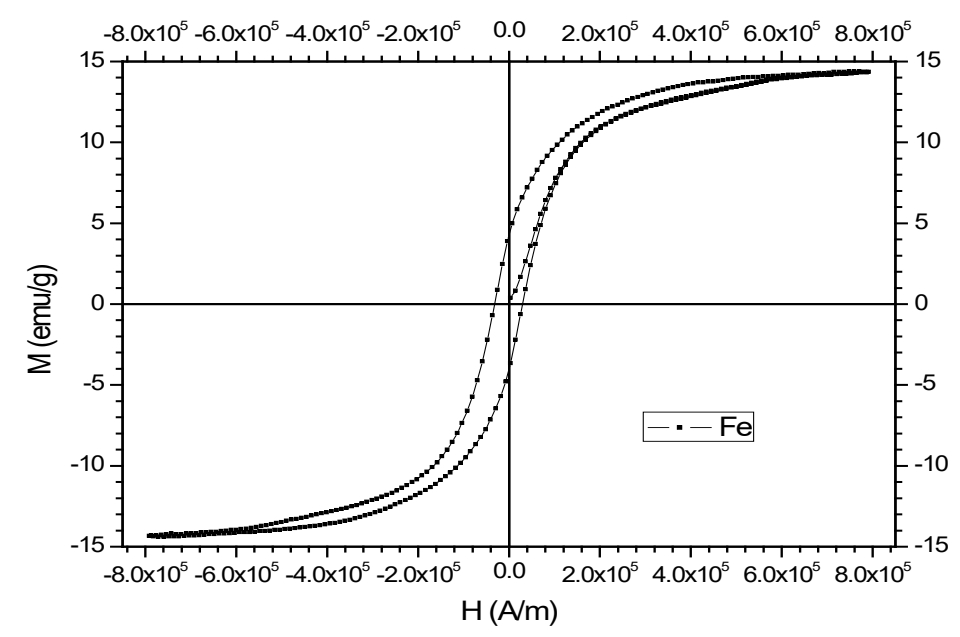

Figure 1: Curve $M=f(H)$ for Fe nanoparticles after purification

performance compared to traditional materials. The use of polymeric matrix composite materials brings many advantages, for example a thermosetting matrix composite material and graphite inclusions may be much stronger than steel. These may be [2]:

- composite materials with magnetic metal matrix (ferromagnetic or ferromagnetic) and with magnetic inclusions. An inclusion of soft magnetic material leads to a large spontaneous magnetization, and one of the hard magnetic material induces a large coercive field.

- composite materials with magnetic metal matrix (generally ferromagnetic - Fe, Co, $\mathrm{Ni}$ etc.) and non-magnetic inclusions (antiferromagnetic, paramagnetic or diamagnetic). The combination of antiferromagnetic ( $\mathrm{CoO}, \mathrm{NiO}, \mathrm{FeS}$ etc.) ferromagnetic leads to an increase of coercivity of the ferromagnetic matrix at room temperature. Composite materials with Co matrix also have high hardness and high resistance to wear and corrosion.

- composite materials with non-magnetic metal matrix and magnetic inclusions. The matrix can be aluminum, $\mathrm{Cu}-\mathrm{Zn}-\mathrm{Al}$, silver, copper or other types of metals. Inclusions include iron fibers, barium ferrite powder, strontium powder, $\mathrm{Fe}-\mathrm{Cr}$ flakes, $\mathrm{SmCo5}$, iron nitrate, iron oxide, $\mathrm{CoFe}$, ferrite etc.
Many magnetic nanoparticles can be synthesized using these precipitation reactions in aqueous solutions. These reactions can generate a wide range of magnetic materials, including spinel or perovskite ferites, metal and metal alloys. Precipitation allows for large amounts of particles to be obtained, but their size distribution is usually high.

\section{Synthesis of Fe Nanoparticles}

$\mathrm{Fe}$ nanoparticles were obtained in the system[22,23]: $\mathrm{FeCl}_{3} \cdot 6 \mathrm{H}_{2} \mathrm{O}-\mathrm{NaBH}_{4}-\mathrm{PEG}$ according to the reaction: $2 \mathrm{FeCl}_{3}+6 \mathrm{NaBH}_{4}$ $+18 \mathrm{H}_{2} \mathrm{O} 22 \mathrm{Fe}^{0}+6 \mathrm{NaCl}+6 \mathrm{~B}(\mathrm{OH})_{3}+$ $21 \mathrm{H}_{2}$.

For the synthesis, the following raw materials were used: $98 \%$ purity iron chloride hexahydrate; reducer - $99 \%$ purity $\mathrm{NaBH}_{4}$ sodium borohydride; ethyl alcohol; PEG polymer-polyethylene glycol. The resulting $\mathrm{Fe}$ nanoparticles were characterized by: Scanning Electron Microscopy (SEM); X-ray diffraction (XRD); X-ray dispersive spectrofluorimetry (EDX); X-ray fluorescence spectrometry (XRF); magnetometry with sample vibration (VSM) at room temperature. The synthesis performed led to iron particles, in the range of $29-108 \mathrm{~nm}$ - figure 1 .

From the magnetic result analysis, the increase in specific saturation magnetisation 
for advanced purified Fe nanoparticles was observed, from $9.39 \mathrm{emu} / \mathrm{g}$ to $14.38 \mathrm{emu} /$ $\mathrm{g}$. There is also an increase in coercive field value, which can be explained by the increase in magnetic interaction forces as a result of particle size reduction.

Using composite materials, enginesthat exhibit almost 3 times smaller core losses can be built. Also, the overall efficiency of the motor can be improved only by replacing the base material. The continued development of composite materials allows the particle size to decrease, resulting in a decrease in application size and approximately $90 \%$ in loss compared to classical materials, and these multiple advantages justify their higher price.

\section{Conclusions}

The use of magnetic materials in the production of composite materials has led to obtaining new properties for them in terms of permeability / magnetostriction, reducing mass and volume for electric machines. Soft magnetic materials have a narrow hysteresis cycle, a low coercive field, high magnetic permeability and magnetic induction. Soft magnets have the property of channelling the magnetic field, but they can not produce it. In these materials we need to know the saturation induction, relative permittivity and frequency behaviour. Hard magnetic materials generate a proper magnetic field and the energy required to maintain the field is accumulated during initial magnetization in a strong outer field so that after removal, the magnet material retains an important residual magnetization, i.e. a saturation magnetization. The performance of electric machines is closely related to the characteristics of the materials used in their construction. The evolution of these materials, especially permanent magnets and ferromagnetic materials, has contributed to improving the performance of electric machines.

\section{References}

[1] Ifrim A., Noțingher P., Materiale electrotehnice, Editura Didactică și Pedagogică, București, 1992, pp 131-156

[2] BordianuA., Modelarea proprietăţilor magnetice ale materialelor compozite, Universitatea Politehnica București, 2012, pp 11-16

[3] Bordianu A.,de la Barrière O., Bottauscio O., Chiampi M., Manzin A., A multiscaleapproach to predict classical losses in soft magnetic composites", IEEE Transactions on Magnetics, vol. 48, nr. 4, 2012, pp. 1537-1540

[4] Bespyatykh Yu. I., KazantsevaN. E., Electromagnetic Properties of Hybrid Polymer Composites, Journal of Communications Technology and Electronics, vol. 53, nr. 2, 2008, pp. 143-154

[5] Legranger J.,Contribution à l'étude des machines brushless à haut rendement dans les applications de moteurs-générateurs embarqués, Docteur de l'Université de Technologie de Compiègn, 2009

[6] Jarrot M.D.,Contribution au développement d'outils de conception de machines synchrones à aimants permanents en vue de l'intégration convertisseur-machine, Docteur de l'Université de Toulouse, 2016

[7] BarreO., Napame B.,Fractional Slot Concentrated Windings: A New Method to Manage the Mutual Inductance between Phases in Three-Phase Electrical Machines and MultiStar Electrical Machines, Machines, vol. 3, 2015, pp. 123-137.

[8] Lagarkov A.N.,Rozanov K.N.,High-frequency behavior of magnetic composites, Journal of Magnetism and Magnetic Materials, vol. 321, 2009, pp. 2082-2092

[9] Gavrilă H., Kappel W., Codescu M.M., Materiale magnetice, Editura Printech, 2005, pp. $98-142$ 
[10] LatebR.,Modelisation des machines asynchrones et synchrones a aimants avec prise en compte des harmoniques d'espace et de temps, 2006, Institut National Polytechnique de Lorraine, Nancy, 2006

[11] MichauxR., LetellierP.,Les Machines Discoïdes à Champ Axial dans les Systèmes dePropulsion Électriques, REE nr.3/1997, pp 37-42

[12] ParvianenA.,PyhönenJ.,NiemeläM.,Axial Flux Interior Permanent MagnetSynchronous Motor with Sinusoïdal Shaped Magnets, ISEF $2001-10^{\text {th }}$ International Symposium on Electromagnetic Fields in Electrical Engineering, Cracow, Poland, September 20-22, 2001

[13] Lettelier P.,Electrical Propulsion Motors, Electric Propulsion; The Effective Solution, IMarest Conference Proceedings, 5-6 October 1995. pp. 71-78.

[14] Mitcham A.J.,Transverse Flux Motors for Electric Propulsion of Ships, IEEColloquium on New Topologies for Permanent Magnet Machines, London, UK, 1997, pp 3/1-3/6.

[15] Willard M. A., KuriharaL. K., CarpenterE. E., CalvinS., HarrisV. G.,Chemically prepared magnetic nanoparticles, International materials reviews,2014, pp. 125- 170

[16] ShiY.,Ding J., Liu X.,Wang J.,NiFe ${ }_{2} \mathrm{O}_{4}$ ultrafine particles prepared by coprecipitationmechanical alloying, Magnetism and Magnetic Materials, 205,1999, pp. 249-254

[17] Zhiqiang J., TangW., ZhangJ., LinH., Du.Y., Magnetic properties of isotropic SrFe12O19 fine particles prepared by mechanical alloying, Magnetism and Magnetic Materials, 1998, pp. 231-237

[18] Chen J., Nikles D.E.,Preparation of acicular $\alpha$-Fe nanoparticles in a lamellar liquid crystalline phase, IEEE Transactions on Magnetics,1996, pp. 4478- 4480.

[19] Chen M., Tang B., Nikles D. E.,Preparation of iron nanoparticles by reduction of acicular $\beta-F e O O H$ particles, IEEE Transactions on Magnetics,1998, pp. 1141-1176.

[20] Krehula S., Popovic S., Music S., Synthesis of acicular $\alpha-\mathrm{FeOOH}$ particles at a very high pH, Materials Letter, 2002, pp. 108-113.

[21] ChakrouneN.,ViauG.,RicolleauC.,FievetF.,Cobalt based anisotropic particles prepared by the polyol process, Materials Chemistry,2003, pp. 312-318

[22] RamadanA., OsamaE., Saha B.,Effects of sodium borohydride as a reductant on the synthesis conditions of Nano-scale Zero Valent Iron, $3^{\text {rd }}$ International Exchange and Innovation Conference on Engineering \& Sciences Kyushu University, Fukuoka, Japan 19-20.10, 2017, pp 39-42

[23] Turabik M., SimsekU.S.,Effect of synthesis parameters on the particle size of the zero valent iron particles, Inorganic and nano-metal chemistry,2017, pp 1033-1042. 